\title{
PENGARUH ROL DINGIN DAN ANIL TERHADAP KARAKTERISTIK STRUKTUR MIKRO DAN KEKERASAN MIKRO PADUAN Zr-0,5\%Nb-Si
}

\author{
Heri Hardiyanti, Arief Sasongko Adhi, Jan Setiawan \\ Pusat Teknologi Bahan Bakar Nuklir - BATAN \\ Kawasan PUSPIPTEK Serpong Gd.20 Tangerang Selatan 15314 \\ e-mail: hrdyanti@batan.go.id
}

(Naskah diterima: 26-5-2020, Naskah direvisi: 9-6-2020, Naskah disetujui: 23-6-2020)

\begin{abstract}
ABSTRAK
PENGARUH ROL DINGIN DAN ANIL TERHADAP KARAKTERISTIK STRUKTUR MIKRO DAN KEKERASAN MIKRO PADUAN Zr-0,5\%Nb-Si. Peningkatan kinerja paduan zirkonium dilakukan dengan menambahkan unsur pemadu yang umum seperti $\mathrm{Nb}$ dan $\mathrm{Si}$ dengan persentase tertentu. Penambahan unsur $\mathrm{Nb}$ akan memberikan pengaruh terhadap struktur mikro yang memberikan ketahanan terhadap iradiasi dan membantu menstabilkan fasa $\beta$ di temperatur kamar, yang terbentuk pada temperatur tinggi. Penambahan unsur $\mathrm{Si}$, akan meningkatkan kekuatan paduan. Telah dilakukan proses sintesis paduan $\mathrm{Zr}-0,5 \% \mathrm{Nb}$-Si dengan menggunakan tungku busur listrik. Paduan ini diamati struktur mikro dan kekerasan mikronya dengan perlakukan proses rol dingin dan perlakuan panas anil. Terlihat dari proses anil tanpa proses rol dingin, menunjukan pembesaran ukuran butir dan penurunkan kekerasan mikro. Paduan yang diberi perlakuan proses rol dingin menunjukkan perubahan struktur mikro di mana densitas deformasi meningkat yang mengakibatkan peningkatan kekerasan mikro. Pemberian perlakuan panas pada paduan yang telah diproses rol dingin mengubah struktur mikro paduan di mana terjadi rekristalisasi dan penurunan densitas deformasi mengakibatkan kekerasan mikro menurun. Ukuran butir dan kekerasan mikro yang paling rendah terjadi pada paduan yang diproses rol dingin $\varepsilon=0,8$ dan dilanjutkan proses anil, dengan nilai berturut-turut sebesar 0,302 mm dan $187 \mathrm{HVN}$.
\end{abstract}

Kata kunci: rol dingin, rekristalisasi, struktur mikro, kekerasan mikro, paduan $\mathrm{Zr}-\mathrm{Nb}-\mathrm{Si}$ 


\begin{abstract}
EFFECTS OF COLD-ROLLING AND ANNEALING ON THE MICROSTRUCTURE AND MICROHARDNESS CHARACTERISTICS OF Zr-0.5\% Nb-Si. The performance improvement of zirconium alloys can be done by adding a certain percentage of common alloying elements such as $\mathrm{Nb}$ and Si. The addition of $\mathrm{Nb}$ provides resistance to irradiation and stabilizes the $\beta$ phase (which normally forms at high temperatures) at room temperature. The addition of Si increases the strength of the alloys. The synthesis of a Zr-0.5\% Nb-Si alloy have been carried out using an electric arc furnace. The microstructure and the microhardness of this alloy were observed after cold-rolling and annealing. It can be seen from the annealed alloy without cold-rolling that the grain size is larger with reduced microhardnes. The alloy treated with cold-rolling shows changes in the microstructure while the deformation density increases, which results in an increase in microhardness. Heat treatment to the cold-rolled alloy changes the microstructure of the alloy where recrystallization occurs, and the deformation density decreases, which results in the decreasing of microhardness. The lowest grain size and microhardness for the alloy that was cold-rolled at $\varepsilon=0.8$ and annealed are $0.302 \mathrm{~mm}$ and $187 \mathrm{HVN}$, respectively.
\end{abstract}

Keywords: cold-roll, recrystallization, microstructure, microhardness, Zr-Nb-Si alloy. 


\section{PENDAHULUAN}

Sejak pertama kali reaktor nuklir digunakan dalam pembangkitan listrik pada tahun 1950-an, paduan zikonium telah digunakan sebagai material kelongsong bahan bakar nuklir reaktor daya, sebagai pengungkung pertama terhadap bahan bakar uranium yang berupa pelet dan produk fisinya. Salah satu solusi yang dikembangkan untuk meningkatkan efisiensi penggunaan bahan bakar, adalah meningkatkan kemampuan fungsi bahan bakar dengan fraksi-bakar yang tinggi. Untuk mencapai kinerja bahan bakar yang sedemikian itu, maka dibutuhkan pengembangan unjuk-kerja bahan bakar dan kelongsong bahan bakar tersebut. Pengembangan kelongsong bahan bakar dapat dilakukan melalui modifikasi paduan bahan kelongsong, dengan cara penambahan unsur ataupun substitusi unsur paduan serta pengujian unjuk kerja logam paduan terhadap pengaruh perlakuan mekanik dan termal bahan kelongsong. Paduan zirkonium dimanfaatkan sebagai bahan kelongsong dikarenakan memiliki karakteristik penampang lintang serapan netron yang rendah, ketahanan terhadap korosi yang tinggi dan juga iradiasi, dan kekuatan mekanik yang sangat baik [1-3].

Pengembangan paduan zirkonium terus dilakukan untuk meningkatkan kinerjanya. Tujuan dari pengembangan ini agar reaktor dapat beroperasi hingga bahan bakar mencapai derajat bakar yang tinggi sehingga dapat memperpanjang waktu siklus bahan bakar. Sejak tahun 1950-an hingga sekarang, paduan zirconium mengalami perubahan bertahap (evolusi) dalam kandungan unsur pemadunya [4], seperti terangkum dalam Gambar 1.

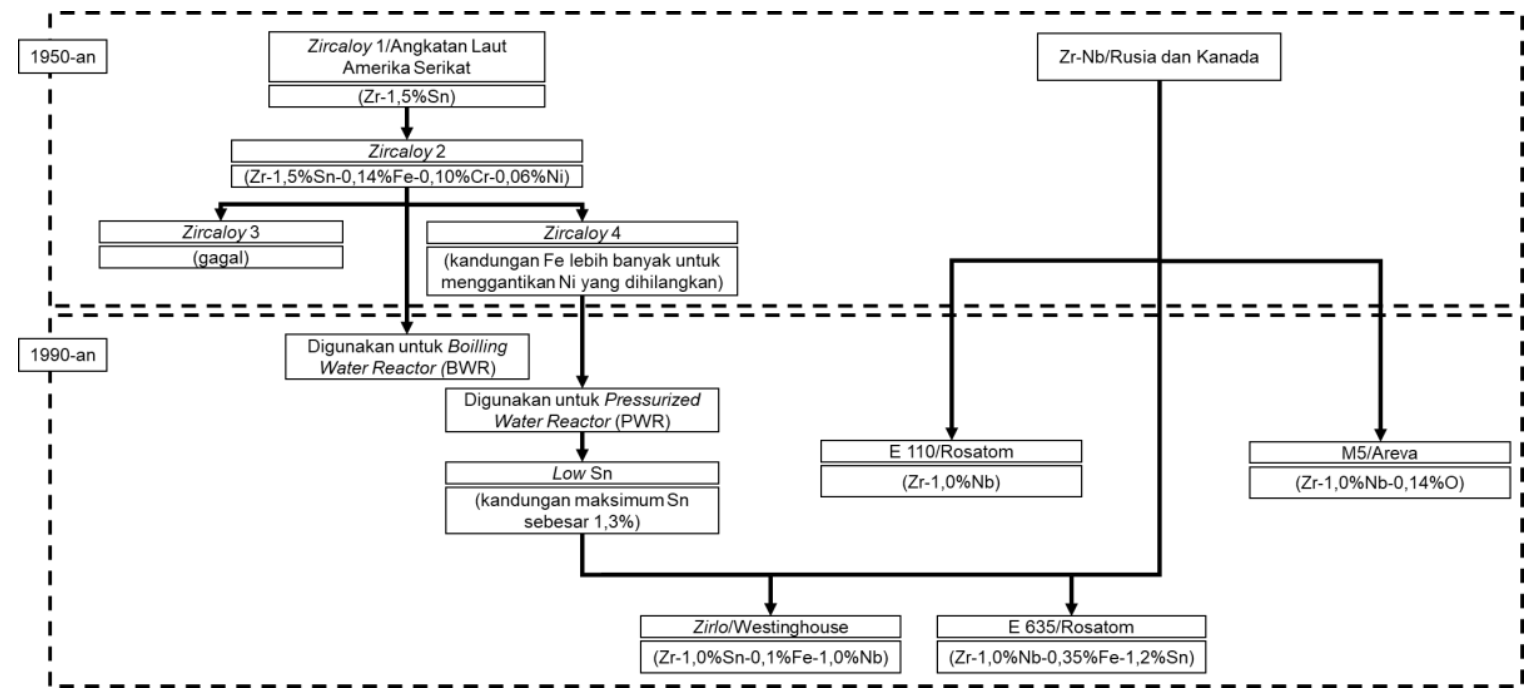

Gambar 1. Evolusi paduan zirkonium untuk kelongsong bahan bakar reaktor dengan pendingin/moderator air ringan (LWR) [4]

Berbagai unsur pemadu telah digunakan untuk meningkatkan kinerja paduan zirkonium, seperti: $\mathrm{Nb}, \mathrm{Si}$ dan $\mathrm{Sn}$, dan unsur pemadu minor seperti: $\mathrm{Fe}, \mathrm{Cr}, \mathrm{Cu}$, Mo dan $O$ [5]. Pada Tabel 1, disajikan karakteristik unsur $\mathrm{Zr}$, Nb, dan $\mathrm{Si}$, yang akan digunakan dalam penelitian ini.

Dari Gambar 2, paduan zirkonium mempunyai tiga daerah perubahan fase. Pertama, fase a yang terbentuk pada tempertur antara $25-86{ }^{\circ} \mathrm{C}$ yang memiliki struktur kristal heksagonal. Kedua, fase $\alpha+\beta$ yang terbentuk pada temperatur $865-963$ ${ }^{\circ} \mathrm{C}$ dengan struktur kristal hexagonal close packed (HCP) dan body center cubic (BCC), dan ketiga di atas temperatur $963^{\circ} \mathrm{C}$ yang berubah menjadi fase $\beta$ yang memiliki struktur kristal BCC, dan pada fase ini paduan menjadi keras, getas dengan karakteristik keuletannya menurun [2]. 
Tabel 1. Karakteristik unsur Zr, Nb, dan Si

\begin{tabular}{lccc}
\hline \multirow{2}{*}{ Karakteristik } & \multicolumn{3}{c}{ Unsur } \\
\cline { 2 - 4 } & $\mathrm{Zr}$ & $\mathrm{Nb}$ & $\mathrm{Si}$ \\
\hline Struktur Kristal & $\mathrm{HCP}$ [6] & $\mathrm{BCC}$ [6] & $\mathrm{FCC}$ [7] \\
Titik leleh (K) & 2128 [8] & 2750 [8] & 1688 [9] \\
Tampang lintang & 0,185 & 1,15 & 0,16 \\
serapan netron & & & \\
termal (barn) [3] & & & \\
\hline
\end{tabular}

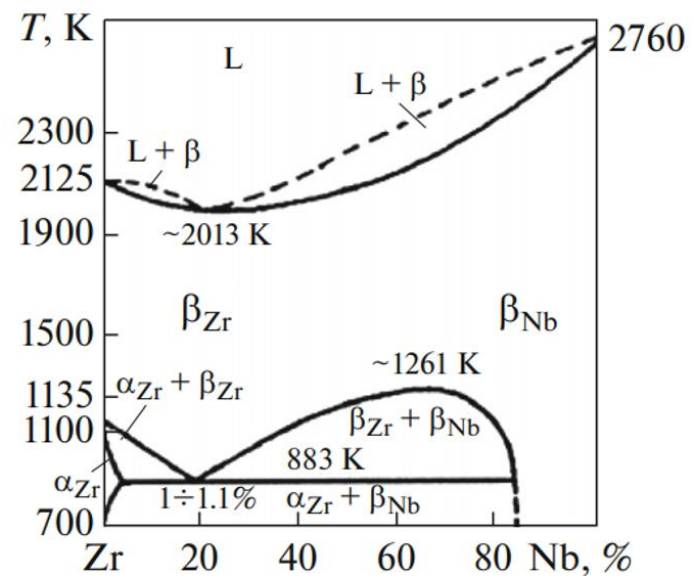

Gambar 2. Diagram fasa biner $\mathrm{Zr}-\mathrm{Nb}$ [6].

Penambahan unsur $\mathrm{Nb}$ ke $\mathrm{Zr}$ dapat menghambat proses rekristalisasi, ukuran butir akan mengecil dan meningkatkan jumlah presipitat yang kaya akan unsur $\mathrm{Nb}$ [10]. Perubahan mikrostruktur dari penambahan $\mathrm{Nb}$ tersebut memberikan keuntungan terhadap kinerja paduan $\mathrm{Zr}$, terutama perilaku degradasi akibat iradiasi [11]. Penambahan unsur $\mathrm{Nb}$ dan unsur Mo, dapat menstabilkan fasa $\beta$ di temperatur kamar, yang terbentuk pada temperatur tinggi [12].

Paduan Zr-Si mempunyai diagram fase yang komplek, seperti ditunjukkan pada Gambar 3. Pada diagram fase Zr-Si dapat dilihat bahwa dengan penambahan Si yang memiliki struktur kristal face center cubic (FCC) dengan persentase berat antara 0,1 sampai $0,25 \%$ pada pemanasan sampai 800 ${ }^{\circ} \mathrm{C}$ akan terjadi fase $\alpha \mathrm{Zr}-\mathrm{Si}$ (Si tidak membentuk fase kedua dengan $\mathrm{Zr}$ ), seperti ditunjukkan pada Gambar 3. Penambahan silikon dapat meningkatkan kekuatan paduan.

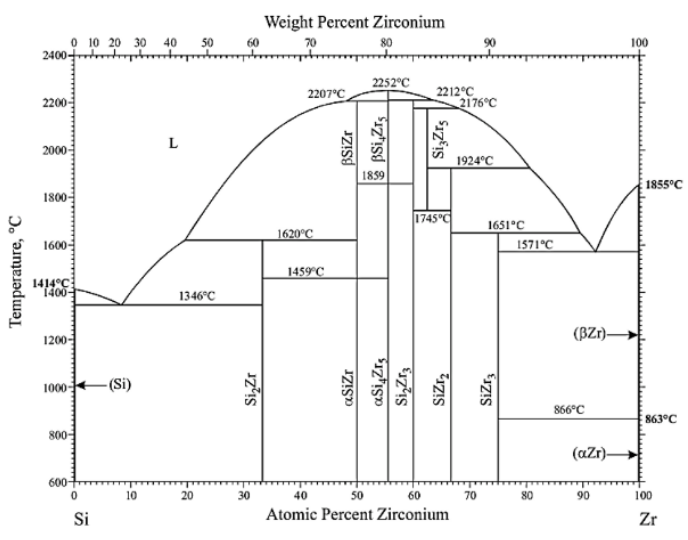

Gambar 3. Diagram fasa biner Zr-Si [7]

Dalam penelitian ini, dilakukan pengamatan terhadap mikrostruktur dan kekerasan mirko pada paduan $\mathrm{Zr}$-Nb-Si yang mengalami deformasi dan proses anil dengan persentase $\mathrm{Nb}$ dalam paduan sebesar $0,5 \%$.

Sebagai simulasi pembentukan kelongsong bahan bakar nuklir dari paduan $\mathrm{Zr}-0,5 \% \mathrm{Nb}-\mathrm{Si}$, dilakukan proses rol dingin. Selama proses rol dingin, pasangan rol secara progresif akan memberi bentuk pada lembaran logam yang diumpankan secara kontinu dengan kelajuan tertentu. Karena proses rol berputar dengan kecepatan permukaan melebihi kecepatan logam yang masuk, gesekan sepanjang kontak antar muka beraksi menarik logam. Logam yang dijepit akan mengalami perpanjangan sebagai kompensasi penurunan luas penampang lintang. Jumlah deformasi yang bisa dicapai pada sekali proses rol tergantung pada kondisi friksi (gesek) sepanjang permukaan.

Perlakuan panas secara umum anil bertujuan untuk merubah bahan, seperti sifat kekuatan dan kekerasan. Proses ini dapat terjadi bila pemanasan yang diberikan melebihi temperatur kristalisasi dan mempertahankan suhu yang sesuai, kemudian dilakuakan pendinginan. Untuk anil bertujuan untuk membuat bahan menjadi ulet dan lunak, menurunkan tekanan internal (tegangan sisa akibat proses rol) dan memperbaiki struktur menjadi lebih homogen. 


\section{METODOLOGI}

Unsur $\mathrm{Zr}$ yang digunakan berupa sponge, sedangkan $\mathrm{Nb}$ dan $\mathrm{Si}$ berupa serbuk. Setiap bahan dipadu dengan persen berat $\mathrm{Nb}$ yang ditentukan sebesar $0,5 \%$ dan persen berat $\mathrm{Si}$ dibuat tetap sebesar $0,25 \%$. Bahan $\mathrm{Zr}$, Nb dan Si dicampur, kemudian bahan yang telah dicampur diberi perlakuan kompaksi dan dilebur dalam tungku peleburan busur listrik. Selama proses peleburan, bahan dilakukan re-melting selama 5 kali. Ingot yang sudah terbentuk dari proses peleburan dipotong menjadi empat bagian untuk dikarakterisasi terpisah. Potongan ingot pertama dilakukan proses metalografi, pengamatan struktur mikro menggunakan mikroskop optik dan uji kekerasan mikro. Bagian kedua diberi perlakuan panas anil pada temperatur $750^{\circ} \mathrm{C}$ dengan waktu tunda selama 3 jam. Setelah pemanasan selesai, dilanjutkan proses metalografi, pengamatan struktur mikro dan uji kekerasan. Bagian ketiga dan keempat, sampel potongan ingot tersebut dilakukan proses rol dingin hingga derajat deformasi sebesar 0,2 dan 0,8. Secara kuantitatif besarnya deformasi ditentukan oleh derajat deformasi $(\varepsilon)$ ini diperoleh dari logaritmik natural perbandingan tebal awal (tbo) dibagi dengan tebal akhir ( $\mathrm{tb}_{\mathrm{i}}$ ) paduan yang diproses rol dingin [13].

$$
\varepsilon=\ln \frac{t b_{o}}{t b_{i}}
$$

Sampel yang telah mengalami rol dingin, dilanjutkan dengan proses metalografi, pengamatan struktur mikro menggunakan mikroskop optik, dan uji kekerasan. Sampel yang telah dirol dingin ini dilanjutkan dengan proses pemanasan anil pada temperatur $750^{\circ} \mathrm{C}$ dengan waktu tunda selama 3 jam. Setelah pemanasan selesai, sampel dikenai proses metalografi kembali untuk diamati struktur mikronya dan diuji kekerasannya.

\section{HASIL DAN PEMBAHASAN}

Setelah proses peleburan dengan tungku busur listrik, dilakukan penimbangan ulang pada paduan $\mathrm{Zr}-\mathrm{Nb}-\mathrm{Si}$ untuk mengetahui seberapa besar kehilangan massa yang terjadi. Pada Tabel 2, disajikan massa tiap unsur untuk memenuhi komposisi yang diinginkan, dan massa setelah peleburan.

Tabel 2. Massa unsur $\mathrm{Zr}$, Nb, dan $\mathrm{Si}$ serta paduan $\mathrm{Zr}-\mathrm{Nb}-\mathrm{Si}$.

\begin{tabular}{clr}
\hline Kode & $\begin{array}{c}\text { Komposisi persentase } \\
\mathrm{Nb} \mathrm{0,5 \%}\end{array}$ & \multicolumn{1}{c}{$\begin{array}{c}\text { Massa } \\
(\mathrm{g})\end{array}$} \\
\hline $\mathrm{A}$ & $\mathrm{Zr}$ & 9,96080 \\
$\mathrm{~B}$ & $\mathrm{Nb}$ & 0,05010 \\
$\mathrm{C}$ & $\mathrm{Si}$ & 0,02525 \\
$\mathrm{D}$ & sebelum dilebur & 10,03615 \\
& {$[$ A+B+C] } & \\
E & sesudah dilebur & 9.96315 \\
F & Selisih [D-E] & 0,07300 \\
\hline
\end{tabular}

Setelah proses peleburan massa ingot lebih rendah dari massa pelet sebelum dilebur. Penurunan massa yang terjadi tidak lebih dari $0,73 \%$. Hal ini sangat dimungkinkan terjadi, karena karakteristik alamiah dari tungku busur listrik bila melebur bahan dari serbuk, meskipun sudah dikompresi berbentuk pelet. Dalam proses peleburan sangat dimungkinkan serbuk $\mathrm{Nb}$ dan/atau $\mathrm{Si}$, pada sisi permukaan yang ikatannya lemah dapat terlepas saat busur listrik mengenai permukaan pelet tersebut. Hal ini terjadi karena adanya interaksi antara tekanan dan panas dari busur listrik.

Struktur mikro dari paduan Zr-0.5\%Nb-Si disajikan pada Gambar 4 hingga Gambar 7. Hasil yang diperoleh, serupa dengan struktur mikro yang diperoleh oleh Jeong [14]. Pada Gambar 4 dan Gambar 5 , terlihat bentuk butir yang jelas dan berbentuk ekuiaksial [15]. Ukuran butir dari paduan $\mathrm{Zr}-0,5 \%-\mathrm{Nb}$ hasil peleburan sebesar $0,302 \mathrm{~mm}$. Pemanasan pada paduan menyebabkan perbesaran pada ukuran butir menjadi sebesar $0,561 \mathrm{~mm}$. 


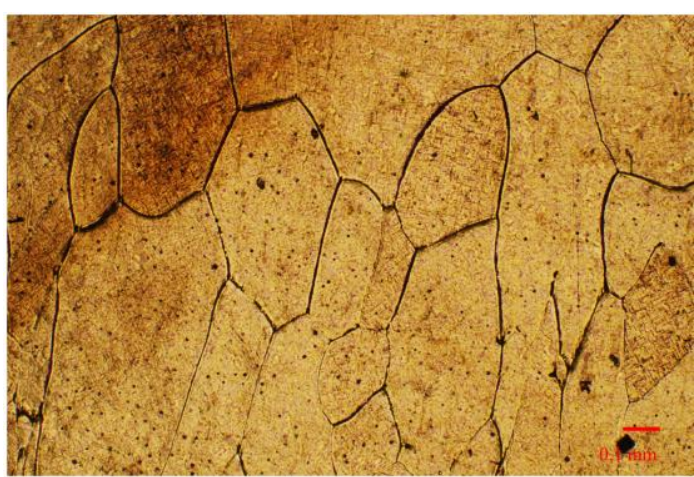

Gambar 4. Struktur

mikro

paduan $\mathrm{Zr}-0,5 \% \mathrm{Nb}-\mathrm{Si}$ hasil peleburan.

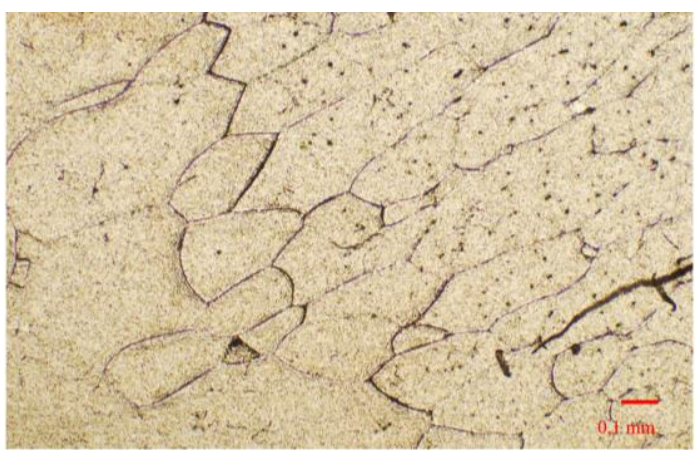

Gambar 5. Struktur mikro paduan Zr$0,5 \% \mathrm{Nb}-\mathrm{Si}$ setelah pemanasan pada temperatur $750^{\circ} \mathrm{C}$ selama 3 jam.

Gambar 6.a dan 7.a menunjukkan bentuk butir memanjang dan rusak yang dapat dikatakan menjadi subbutir yang diakibatkan oleh proses pengerolan. Dari citra yang dihasilkan mikroskop optik, bentuk butir setelah proses rol dingin sulit untuk diamati sehingga tidak bisa ditentukan ukuran butirnya. Setelah mengalami pemanasan terlihat ukuran butir relatif menjadi besar seperti ditunjukkan pada Gambar 6.b dan 7.b. Hal ini terjadi diakibatkan proses pemanasan anil pada temperatur $750^{\circ} \mathrm{C}$ memulihkan bentuk butir yang rusak di mana terjadi rekristalisasi dan pertumbuhan butir. Pemulihan inipun, mengurangi dan sangat dimungkinkan menghilangkan cacat atau tegangan sisa akibat dislokasi yang terjadi saat proses pengerolan. Ukuran butir paduan $\mathrm{Zr}-0,5 \% \mathrm{Nb}-\mathrm{Si}$ setelah proses pengerolan berurut-turut adalah $0,561 \mathrm{~mm}$ untuk paduan dengan derajat deformasi rol dingin $\varepsilon=0,2$, dan $0,302 \mathrm{~mm}$ untuk paduan dengan derajat deformasi rol dingin $\varepsilon=0,8$.

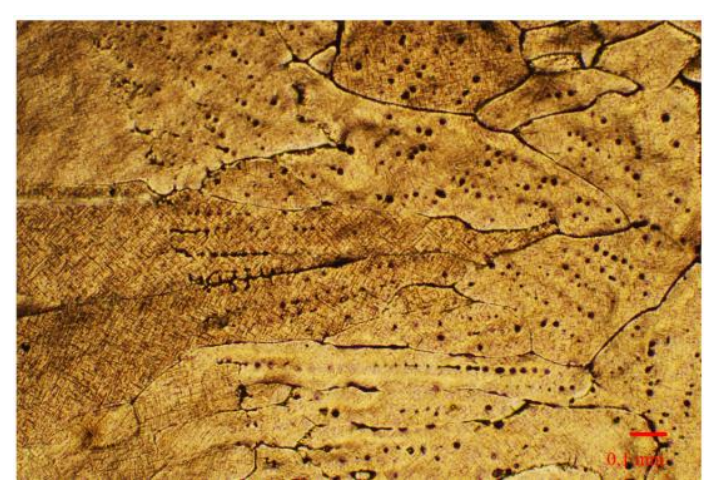

(a)

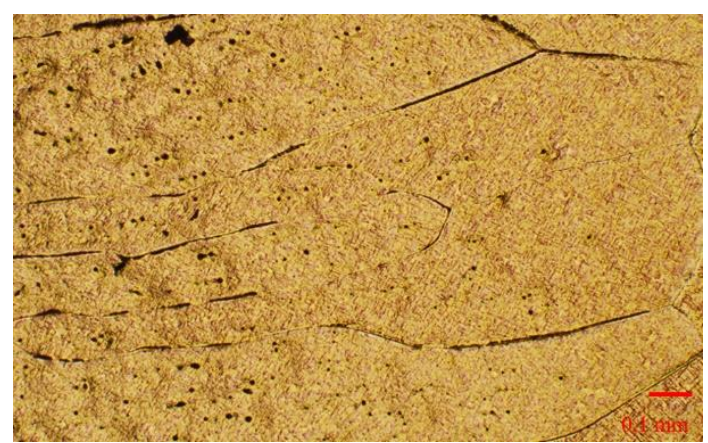

(b)

Gambar 6. Struktur mikro paduan $\mathrm{Zr}-0,5 \% \mathrm{Nb}-\mathrm{Si}$

(a) hasil rol dingin dengan $\varepsilon=0,2$

(b) setelah pemanasan lanjutan pada temperatur $750^{\circ} \mathrm{C}$ selama 3 jam. 


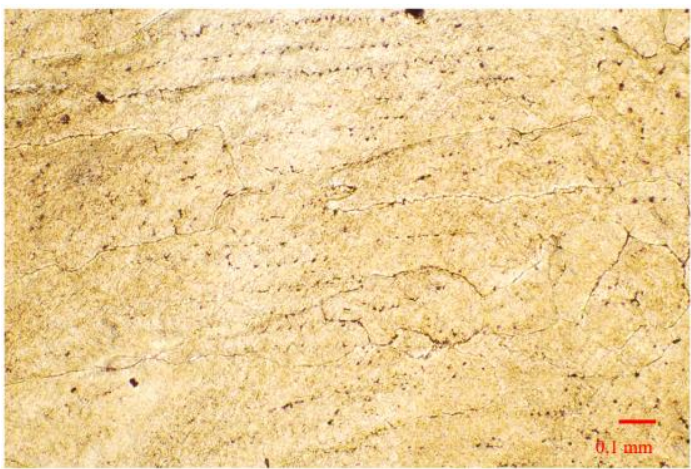

(a)

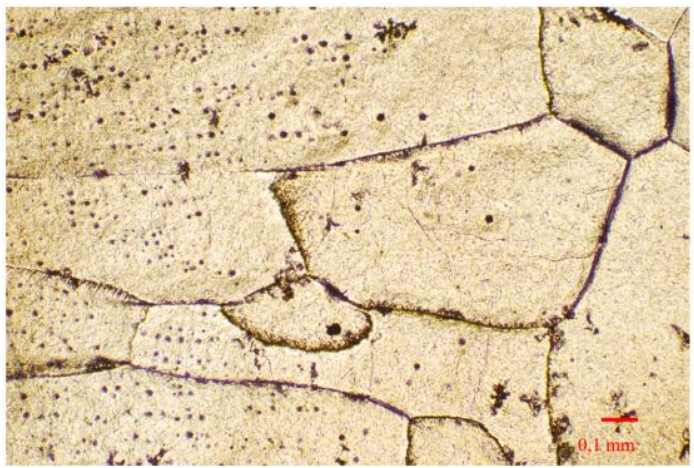

(b)

Gambar 7. Struktur mikro paduan $\mathrm{Zr}-0,5 \% \mathrm{Nb}-\mathrm{Si}$

(a) hasil rol dingin dengan $\varepsilon=0,8$

(b) setelah dilanjutkan dengan pemanasan pada temperatur $750^{\circ} \mathrm{C}$ selama 3 jam.

Perubahan kekerasan paduan $\mathrm{Zr}$ $0,5 \% \mathrm{Nb}$-Si selama dikenai proses disajikan pada Gambar 8.

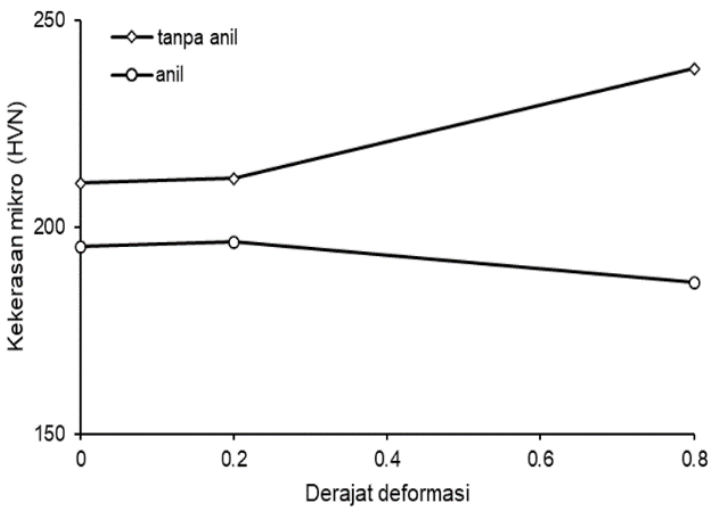

Gambar 8. Perubahan kekerasan terhadap derajat deformasi proses rol dingin.
Dari Gambar 8 tersebut terlihat bahwa seiring dengan semakin tinggi derajat deformasi proses rol dingin tanpa anil menunjukan kecenderungan meningkat pada kekerasan mikro pada paduan, berkebalikan dengan paduan yang dikenai anil menunjukan kecenderungan kekerasan mikro yang menurun. Pendekatan secara linier untuk data tersebut diperoleh persamaan 2 untuk kondisi tanpa anil dan persamaan 3 untuk kondisi anil.

$$
\begin{aligned}
& H_{v}=36,7 \varepsilon+207,9 \\
& H_{v}=-12,2 \varepsilon+196,8
\end{aligned}
$$

dengan $\mathrm{H}_{\mathrm{v}}$ adalah kekerasan mikro dalam HVN dan $\varepsilon$ adalah derajat deformasi. Persamaan tersebut menunjukkan derajat deformasi yang dicapai dalam proses rol dingin pada paduan $\mathrm{Zr}-0,5 \% \mathrm{Nb}-\mathrm{Si}$ akan meningkatkan kekerasan mikro paduan. Dari hasil struktur mikro menunjukan bentuk butir yang memanjang dan rusak. Mekanisme peningkatan kekerasan mikro paduan disebabkan oleh deformasi dengan meningkatnya densitas dislokasi dari proses rol dingin. Densitas dislokasi ini akan berkurang selama proses anil sehingga, kekerasan mikro yang disebabkan oleh deformasi tersebut menjadi berkurang.

\section{SIMPULAN}

Setelah paduan $\mathrm{Zr}-0,5 \% \mathrm{Nb}-\mathrm{Zr}$ diberi perlakuan panas, terjadi perubahan struktur mikro di mana terjadi perubahan ukuran butir dan kekerasan mikronya. Pengerjaan proses rol dingin pun secara signifikan mempengaruhi struktur mikro dan kekerasan mikro paduan. Ukuran butir dan kekerasan mikro yang paling rendah terjadi pada paduan yang rol dingin dengan $\varepsilon=0,8$, dengan nilai berturut-turut sebesar $0,302 \mathrm{~mm}$ dan 187 HVN. Peningkatan kekerasan mikro paduan yang dikenai proses rol dingin dikarenakan oleh terjadinya deformasi cacat struktur dan adanya tegangan sisa. Perlakuan panas akan meningkatkan ukuran butir sehingga kekerasan mikro akan 
menurun seiring dengan menurunnya densitas dislokasi. Ketika derajat deformasi proses rol semakin tinggi, terjadi peningkatan deformasi cacat yang menyebabkan peningkatan kekerasan mikro.

\section{UCAPAN TERIMA KASIH}

Pada kesempatan ini para penulis mengucapkan terima kasih kepada mantan koordinator kegiatan bahan kelongsong dan struktur dukung, Ir. Futichah, M.T. atas bimbingannya, seluruh operator di IEBE yang telah membantu melaksanakan penelitian ini dan kepada Kepala Bidang Fabrikasi Bahan Bakar Nuklir yang sudah memfasilitasi dan mendukung kegiatan penelitian dan pengembangan kelongsong bahan bakar nuklir di IEBE.

\section{DAFTAR PUSTAKA}

[1]. H. Yang, et.al. "Effects of alloying elements ( $\mathrm{Sn}, \mathrm{Nb}, \mathrm{Cr}$, and $\mathrm{Mo}$ ) on the microstructure and mechanical properties of zirconium alloys," Journal of Nuclear Science and Technology, vol. 52, no. 9, pp. 1162-1173, 2015.

[2]. T. L. Yau, V. E. Annamalai, "Corrosion of zirconium and its alloys," Material Sciences and Materials Engineering, vol. 3, pp. 2094-2134, 2016.

[3]. Z. Duan, et. al. "Current status of materials development of nuclear fuel cladding tubes for light water reactors," Nuclear Engineering and Design, vol. 316, pp. 131-150, 2017.

[4]. A. T. Motta, et. al. "Corrosion of zirconium alloys used for nuclear fuel cladding" Annuual Review of Materials Research, vol. 45, pp. 311-343, 2015.

[5]. B. F. Luan, et. al. "Growth behavior study of second phase particles in a $\mathrm{Zr}$ $\mathrm{Sn}-\mathrm{Nb}-\mathrm{Fe}-\mathrm{Cr}-\mathrm{Cu}$ alloy," Journal of Nuclear Materials, vol. 423, no.1-3, pp. 127-131, 2012.

[6]. A. Smirnov, et.al. "Thermal diffusivity of zirconium-niobium alloys at high temperatures" High Temperature, vol. 55, no. 3, 2017.
[7]. H. Okamoto, "Supplemental literature review of binary phase diagrams: $\mathrm{Ag}-\mathrm{Ni}$, $\mathrm{Ag}-\mathrm{Zr}, \mathrm{Au}-\mathrm{Bi}, \mathrm{B}-\mathrm{Ni}, \mathrm{Co}-\mathrm{Sb}, \mathrm{Cu}-\mathrm{Mn}, \mathrm{Cu}-$ $\mathrm{Si}, \mathrm{Cu}-\mathrm{Zn}, \mathrm{Fe}-\mathrm{Zr}$, Li-Sb, Mg-Pu, and Si$\mathrm{Zr}$ " Journal of Phase Equilibria and Diffusion, vol. 39, no.1, pp. 87-100, 2018.

[8]. De-Ye, et. al. "An n-body potential for a $\mathrm{Zr}-\mathrm{Nb}$ system based on the embeddedatom method" Journal of Physics: Condensed Matter, vol. 25, no.10, 2013.

[9]. I. V. Talyzin, et. al. "Size dependence of the melting point of silicon nanoparticles: molecular dynamics and thermodynamic simulation," Semiconductors, vol. 53, no. 7, pp. 947-953, 2019.

[10].H. L. Yang, et.al. "Microstructural evolution and hardening effect in lowdose self-ion irradiated $\mathrm{Zr}-\mathrm{Nb}$ alloys," Journal of Nuclear Materials, vol. 542, 2020.

[11]. Q. Dong, et. al. "Irradiation damage and hardening in pure $\mathrm{Zr}$ and $\mathrm{Zr}$-Nb alloys at $573 \mathrm{~K}$ from self-ion irradiation" Materials \& Design vol.161, pp. 147-159, 2019.

[12]. H. Yu, Z. Yao, and M. R. Daymond. "The stability of thermodynamically metastable phases in a $\mathrm{Zr}$-Sn-Nb-Mo alloy: Effects of alloying elements, morphology and applied stress/strain" Journal of Nuclear Materials, vol. 493, pp. 84-95, 2017.

[13]. M. Mišović, et. al. "Deformations and velocities during the cold rolling of aluminium alloys" Materiali in tehnologije vol. 50, no. 1, pp. 59-67, 2016.

[14]. G. B. Jeong, I. W. Kim, and S.I. Hong, "Influence of microstructure modification on the circumferential creep of $\mathrm{Zr}-\mathrm{Nb}$ $\mathrm{Sn}-\mathrm{Fe}$ cladding tubes," Journal of Nuclear Materials, vol. 468, pp. 171-177, 2016.

[15]. S. Ko, et. al. "Deformation behavior of cold-rolled and annealed $\mathrm{Zr}-1.5 \mathrm{Nb}$ and $\mathrm{Zr}-1.5 \mathrm{Nb}-\mathrm{S}$ alloys" Journal of Nuclear Materials, vol. 414, no. 2, pp.138-144, 2011. 